\title{
Erratum to: Barriers and Facilitators to Recruitment to a Culturally Based Dietary Intervention Among Urban Hispanic Breast Cancer Survivors
}

\author{
Blanca Bernard-Davila $^{1}$ - A. Corina Aycinena ${ }^{1,2,3}$ - John Richardson ${ }^{1}$. \\ Ann Ogden Gaffney ${ }^{5} \cdot$ Pam Koch $^{3} \cdot$ Isobel Contento ${ }^{3}$. Christine Sardo Molmenti ${ }^{1,2}$. \\ Maria Alvarez $^{2}$ - Dawn Hershman ${ }^{1,2,4}$ - Heather Greenlee ${ }^{1,2}$
}

\section{Erratum to: J. Racial and Ethnic Health Disparities (2015)}

\section{2:244-255}

DOI 10.1007/s40615-014-0076-5

In the original article, the sources of funding support were incorrectly reported. The following three grants are the correct sources of funding for this study: R21CA152903, UL1TR000040, and NCI 5T32CA009529.

The online version of the original article can be found at http://dx.doi.org/ 10.1007/s40615-014-0076-5.

\section{Heather Greenlee}

hg2120@columbia.edu

1 Department of Epidemiology, Mailman School of Public Health, Columbia University, 722 West 168th St., 7th Floor, New York, NY 10032, USA

2 Herbert Irving Comprehensive Cancer Center, Columbia University, Medical Center, New York, NY, USA

3 Department of Health and Behavior Studies, Teachers College, Columbia University, New York, NY, USA

4 Department of Medicine, College of Physicians and Surgeons, Columbia University, New York, NY, USA

5 Cook For Your Life, New York, NY, USA 